\title{
REFLECTIONS ON THE PRODUCTION OF URBAN SPACE IN BRAZIL AND ITS CITIES
}

\section{Richard Wilson Borrozine De Siqueira1 and Camila Rodrigues Da Fonseca²}

${ }^{1} \mathrm{MsC}$. in Economics at PUC-SP, Professor of Economics and Finance at Federal Institute of Brasilia (IFB); Student of Doctorate at Post Graduate Program in Human Geography, University of Brasilia(UNB),Brazil, ricwbs@ig.com.br

2 Specialist in Fashion and Design at UDESC, Professor of History, Fashion and Design at Federal Institute of Brasilia (IFB), Brazil, micamoda@uol.com.br

\begin{abstract}
This article aims to present reflections on the production of urban space in Brazil during the process of industrialization and urbanization that occurred in the country since the early twentieth century to the present day. In the article, in addition to reflections, we discuss some historical processes and policies through tables, map and data. In the world, the country has one of the largest territories, population and economy and faced several difficulties since its formation through historical processes that include the situation of colony, slavery, empire and independence with subsequent establishment of a federal republic, with episodes of autocracy still in the twentieth century. The country went from agricultural exporter to the condition of industrial and agricultural power after a long process of transformations that drove the country's economy. The state planning associated with the performance of major domestic and foreign capital in Brazil allowed the country get high growth rates in the twentieth century with similar numbers at times to the current China. An intense process of transformation occurred in the country with the stabilization of the economy post-1994 and deepening of social policies more structured after 2002. Along the described historical process, the production of space in the urban centers brought bad consequences to population of many cities in the country and also reactions against precariousness of urban facilities, lack of sanitation, social exclusion, among others. Brazilian activists and thinkers from diverse backgrounds had created intellectual perspectives about the described issues as Mílon Santos, Paulo Freyre and Celso Furtado, among them, for example. Several issues related to human sciences including geography, sociology, economics etc in Brazil are not consensual and are still open to deep reflection in the academic literature. In this sense, it is necessary to expand reflections on these processes and for that we present this study on the production of urban space in Brazil and its consequences throughout the twentieth century to the present day. As conclusion, despite some efforts and relatively successful policies to treat some of the most critical social problems as income concentration, poverty and exclusion of significant segments of the population, the fact is that Brazilian cities are still suffering with bad conditions related to the production of urban space. The ethos of capitalist conservative modernization that occurred in Brazil over time was not able to eliminate some of its contradictions and more reflections are necessary in the sense to create better effective policies and improve the well-being of the population.
\end{abstract}

Keywords: Production, Space, Cities, Brazil, Urban. 


\section{INTRODUCTION}

This article aims to present reflections on the production of urban space in Brazil during the process of industrialization and urbanization that occurred in the country since the early twentieth century to the present day.

Initially, we present an overview of the territorial expansion and growth of urban areas in Brazil. The following are presented a sample of the current Brazilian urban problems. Among these problems, social inequality, segregation, poverty and contradictions in the production of urban space and limitations of planning. These are objects of our critical reflection. In conclusion, we present some reflections on the production of urban space in the country and its cities in general.

Throughout the text we present some views of important scholars on the subject of cities and urbanization, particularly as regards the production of urban space in capitalism and its consequences in terms of spatial justice considering multiple rights, including the right to the cities. By exploring contradictions, it is expected to contribute to a critical reflection in the Brazilian and international geographical thought in this regard.

\section{PROCESSES OF TERRITORIAL EXPANSION AND GROWTH OF URBAN AREAS IN BRAZIL: AN OVERVIEW}

The current Brazilian territory was inhabited long before of recognized limits that begins in 1500 in the context of Iberian expansionist project. From the point of view of the Indians the Brazilian territorial expansion was a destructive invasion of his people and in the colonizer's perspective a process that giving genesis to the people (Moraes, 2005, p 138). The existence of previous populations is recognized at archaeological studies. To the official story, the first two Brazilian cities are São Vicente founded in 1532, and in 1549 is founded Salvador, the first capital of the country (Geiser, 1963).

Over the centuries were adopted various strategies to populate the territory and keep it safe from conflicts. Among these strategies, the creation of the system of hereditary captaincies in which lands were granted to family management linked to Portuguese crown. The promotion of expeditions looking for riches and territorial demarcations fed internalization of towns. Most of Brazilian people is located in the Atlantic coast until the current days. Other key aspects in the configuration of territory included the logistics of production and consumption, natural limitations, culture, climate etc. Is recognized the capacity of Brazil to overcome territorial disputes with neighboring countries and European powers over the centuries mainly in the context of diplomatic negotiations. During the process of creation national identity besides the autochthonous originally habitants, many cultures originated from various regions in the world as Africans, Europeans, Arabs, Asians and others contributed to syncretism the Brazilian culture.

In the economic sphere many activities were done from the fifteenth century to the late nineteenth century, for instance, the cultivation of sugar cane, cocoa, coffee, tea, hinterland drugs, wood, rubber, and livestock among others. These activities spread throughout the territory were aimed predominantly to foreign market. Huge farms and slave labor were some of the basic features of production in the end of nineteenth century. With the end of slavery at same period there are new possibilities for structuring a capitalism based on free labor in the country. Until the early twentieth century Brazil has just a few urbanized cities. After this period, the country experience an intense growth of urbanization and industrialization that culminated on the creation and expansion of big towns in the early twentieth century. 
Table 1: Brazilian Population, Urban and Rural

\begin{tabular}{|c|c|c|c|c|}
\hline & Year & $\begin{array}{l}\text { Population } \\
\text { (in millions) }\end{array}$ & Urban (\%) & Rural (\%) \\
\hline & 1550 & 0,015 & No data & No data \\
\hline & 1600 & 0,1 & No data & No data \\
\hline & 1700 & 0,3 & No data & No data \\
\hline & 1800 & 3,25 & No data & No data \\
\hline & 1900 & 17,43 & No data & No data \\
\hline & 1940 & 41,23 & 31,24 & 68,76 \\
\hline & 1950 & 51,94 & 36,16 & 63,84 \\
\hline 1960 & & 70,07 & 44,67 & 55,33 \\
\hline 1970 & & 93,14 & 55,92 & 44,08 \\
\hline 1980 & & 119,00 & 67,59 & 32,41 \\
\hline 1990 & & 146,82 & 75,59 & 24,41 \\
\hline 2000 & & 169,80 & 81,24 & 18,76 \\
\hline 2010 & & 190,75 & 84,36 & 15,64 \\
\hline 2015 & & 204,00 & 86,00 & 14,00 \\
\hline
\end{tabular}

Source: Instituto Brasileiro de Geografia Estatística(IBGE).

Between 1930 and 1960 there is an association between domestic private capital, foreign, and expansion of public investments in infrastructure. There is creation of state-owned enterprises like Petrobras in the context of import substitution strategy bringing profound changes to Brazilian society. The "Modernization Conservative" in fact, resulted in a fast process of industrialization and the expansion of cities and towns throughout the twentieth century. Moraes (2005, p.97) cites that the Estado Novo (1930) with Getúlio Vargas brought the first definition of regions to the country. In the same government there is an encouragement to "March to the West" in order to occupy this region and supply the southeast region with raw materials. The accelerated industrialization ends with the isolation of regional markets and helps to build a national domestic market with production of manufactured in the Southeast which includes cities such as São Paulo, Rio de Janeiro, Minas Gerais and Espirito Santo. This region is the main supplier of industrialized goods for others states. The southeast region turns out to concentrate population, urban centers, and important infrastructures and is characterized by the existence of big cities in general. A process of metropolization occurs in the region.

In 1964 a military coup occurs in the country and it goes until 1985. The military intensified projects of economic expansion and exploitation of the country. Construction of new infrastructure, creation new state-owned enterprises and expansion of the process of industrialization to its most advanced stage: the production of capital goods. In the territory, the administration expanded its efforts in direction to the northern and Amazonia. In the period of autocracy military many cruel atrocities against population were done. They also had their contribution to the Urban Crises and environment Crises in the context of many policies done by them.

Besides the urban concentration, we had as basic characteristics, unequal pace of urbanization that reflected economic and regional differences. Among the legacies of the urbanization and industrialization process we had the expansion of regional inequalities, rural exodus as result of technical modernization in the countryside and land ownership concentration and "attractivity and benefits" of the cities. Also, the creation of large metropolises and urban centers were facilitated by the expansion of infrastructure, communications and transport leading in the end to unification of the internal market.(See Table 1)

The Brazil is divided into North, Northeast, Southeast, South and Midwest. The last one, was occupied irregularly over time, initially pioneers seeking riches and after some time encouraged by the state and by low land prices. The creation of Brasilia and roads were essential steps to connect the country and to others states like Goias and Mato Grosso. Also helped the urbanization of some cities in the region the intensification of mechanization at large landed property focused on livestock production, soybeans and cereals since the seventies. The southern region had a relative industrialization process until the early 70 s. The region had the family production as basic characteristic which contributed to restrict the rural exodus in certain periods, but 
with the increase of the use of technology and concentration of lands, part of people took the direction of urban centers and agricultural frontiers to the Midwest and Amazonia, for instance. In the Northeast, urbanization of cities was less intense in view of the regional agricultural characteristics, climate, traditional smallholders etc. These characteristics initially limited the rural exodus, but with the increased of the use of technology and concentration of lands many people went to live in urban centers. The Northeast has problems traditionally linked to the dry climate and prevailing political and social structures. In the North region there was a slower growth and the process of urbanization was limited. In spite of it, in the last decades there is an intensification of migration in the states of Pará, Rondônia and Tocantins, predominantly rural. Some development burocratic organisms were created in the past by the government like the SUDENE, SUDAM etc. to minimize regional differences without great success.

Moraes (2005, p 139) points out that the role of the state in Brazil It is thus the enabler of the conquest of land settlement, inducer, provider of equipment, land use manager[...], the guardian of the territorial funds, and guarantee of territorial integrity, the supreme value of the national geopolitical and general assumption". In the nineties the notion of the state's acting range in the economy and related to the rights in general started to change. With globalization, the country enters into new capital appreciation strategies. The government directs efforts to catalyze these capitals and stabilize the economy in 94 . Some public policies are adopted since this period. Urban problems like lack of public investments and mass unemployment has grown with neoliberal policies in the sense that are based in gentrification process leading to social exclusion of significant parcels of population.

In general it can be said that Brazil has maintained in recent decades accelerated urbanization process with the internalization of population, including in areas of economic frontier and medium-sized cities. The periphery of urban centers associated with social-spatial segregation and the high costs of living are basic elements of capitalist society that produces urban spaces associated with the construction industry, real estate, banks and global financial markets. This complex process helps to expel even more population groups to peripheries. Agglomerations and dynamics of employment and migration are also strongly related to the country's urban dynamics. Many cities were made thinking in buildings and automobiles which brings problems in terms of mobility, traffic jam, environment and public transport contributing to worsens of welfare conditions. The Urban Crisis in Brazil and in many other countries are strictly linked to production of space.

\section{PRODUCTION OF URBAN SPACE IN BRAZIL AND RIGHT TO THE CITY: SOME REFLECTIONS}

Existing problems lead us to affirm the respect of an urban crisis. Although there are distinctions in size and profile of the cities, there are usually problems common to cities: Violence, Criminality, Pollution, Traffic Jam, Waste disposal problems, sanitation, lack of services, education, health, recreation, housing, energy, lighting, public transport, risk of landslides, floods, unemployment, accessibility, conflicts over land etc.

Table 2: Average percentage of adequacy of Households per city groups 1991/2000

\begin{tabular}{|l|l|l|l|l|l|l|l|}
\hline Period & $\begin{array}{c}\text { Big centers in } \\
\text { conurbated } \\
\text { area }\end{array}$ & $\begin{array}{c}\text { Peripheries } \\
\text { of big cities }\end{array}$ & $\begin{array}{c}\text { Regional } \\
\text { centers } \\
\text { conurbated }\end{array}$ & $\begin{array}{c}\text { Peripheries } \\
\text { of regional } \\
\text { centers }\end{array}$ & $\begin{array}{c}\text { Large } \\
\text { cities } \\
\text { isolated }\end{array}$ & $\begin{array}{c}\text { Sub } \\
\text { regional } \\
\text { Centers }\end{array}$ & Locality \\
\hline 1991 & $34,0 \%$ & $21,6 \%$ & $30,5 \%$ & $21,0 \%$ & $25,0 \%$ & $17,8 \%$ & $9,0 \%$ \\
\hline 2000 & $43,2 \%$ & $24,3 \%$ & $41,3 \%$ & $30,7 \%$ & $35,7 \%$ & $32,1 \%$ & $17,0 \%$ \\
\hline
\end{tabular}

Source: Relatório das Cidades(2009).

According to "Relatório das Cidades(2009, p.18)" Brazil has "adequacy of Households" in $22.74 \%$ in 1991 and $33.00 \%$ in 2000. In the new Census of IBGE done in 2010 the percentage of municipalities with missing or some inappropriate sanitary item is $38 \%$. Another fact is that in 1991 the percentage of municipalities with $0 \%$ of adequate households was $52.61 \%$ and $16.58 \%$ in 2000 . Criteria used in "Relatório das Cidades(2009, p.18)" observes sanitation, water, sewer, electricity, garbage collection etc.(See Table 2, Average percentage of adequacy of Households per city groups 1991/2000)

Brazil is not anymore a member of hunger map and has grown in recent years as well. The country has adopted some successful public policies in many areas, despite some inconsistencies. However is clear that problems related to urban poverty have not yet been resolved in the face of systemic contradictions and historical legacies. According to Cidade (2010, p.195) "in Brazil, a large extent, cities are characterized by socio-spatial segregation and inequality". Also Ribeiro (2015, p.171) points out that in Brazilian urbanization, the link 
between sociospatial segregation and resistance in urban areas acquire different nuances. Among the specifics that we want to highlight, we have the inequality carried out mainly by the formation of private ownership of land and the construction of a sociability that is played under the auspices of authoritarian relations. They make up a breeding nucleus of a society that naturalizes holdings, expropriations, the hierarchies, poverty, dispossession, and that is clearly expressed in the current landscape of cities. These contents by production of urban space are very advantageous to the advancement of global capital strategies to produce, paradoxically, a close relationship between the archaic and the modern.

Associated with the class ideologies based on happiness through consumption and property there is a valuation process of certain spaces in Brazil's urban centers that leads to the expulsion of population groups. Carlos (2015, p. 20) points that reflecting today over the town in Brazil means think of it as materialization of the process of "dependent urbanization" in which the contradictions emerge more in blatant manner; where the accumulation of wealth pari passu to the misery leads to a different type of claim, compared from those emerging in the developed countries. Here still hangs an uphill struggle for minimum living conditions for basic rights already conquered by those countries.

Santos (2013, p 21) criticizes partial treatments of urban poverty remembering in some versions for whom "Urban Crisis" is a result of population demographic pressure or for others whom only care about poverty policy implications as well as the dangers of a potential explosion. As observes Santos (2013, p.21) these two approaches "One who seeks to avoid the problem of poverty, one that selects certain aspects of reality - are becoming slogans multiplied by media Mass". And concludes "as theories are inconsistent, it is very simple to impose a form of planning that does not lead to anything". Throughout the history of Brazil, especially in the twentieth century, there is intensification of urbanization. The country currently has big urban centers like São Paulo, Rio de Janeiro, Salvador, Belo Horizonte, Recife, Porto Alegre, Distrito Federal, Fortaleza, Curitiba, Manaus, Campinas, between others. Currently, the country has 204 million people spread across some 6000 municipalities in 26 states and the Federal District. (See Fig.1). 
Fig.1 Brazil: size of Municípios and Metropolitan areas in 2010.

\section{Brazil: Size of Municipios and Metropolitan Areas in 2010}

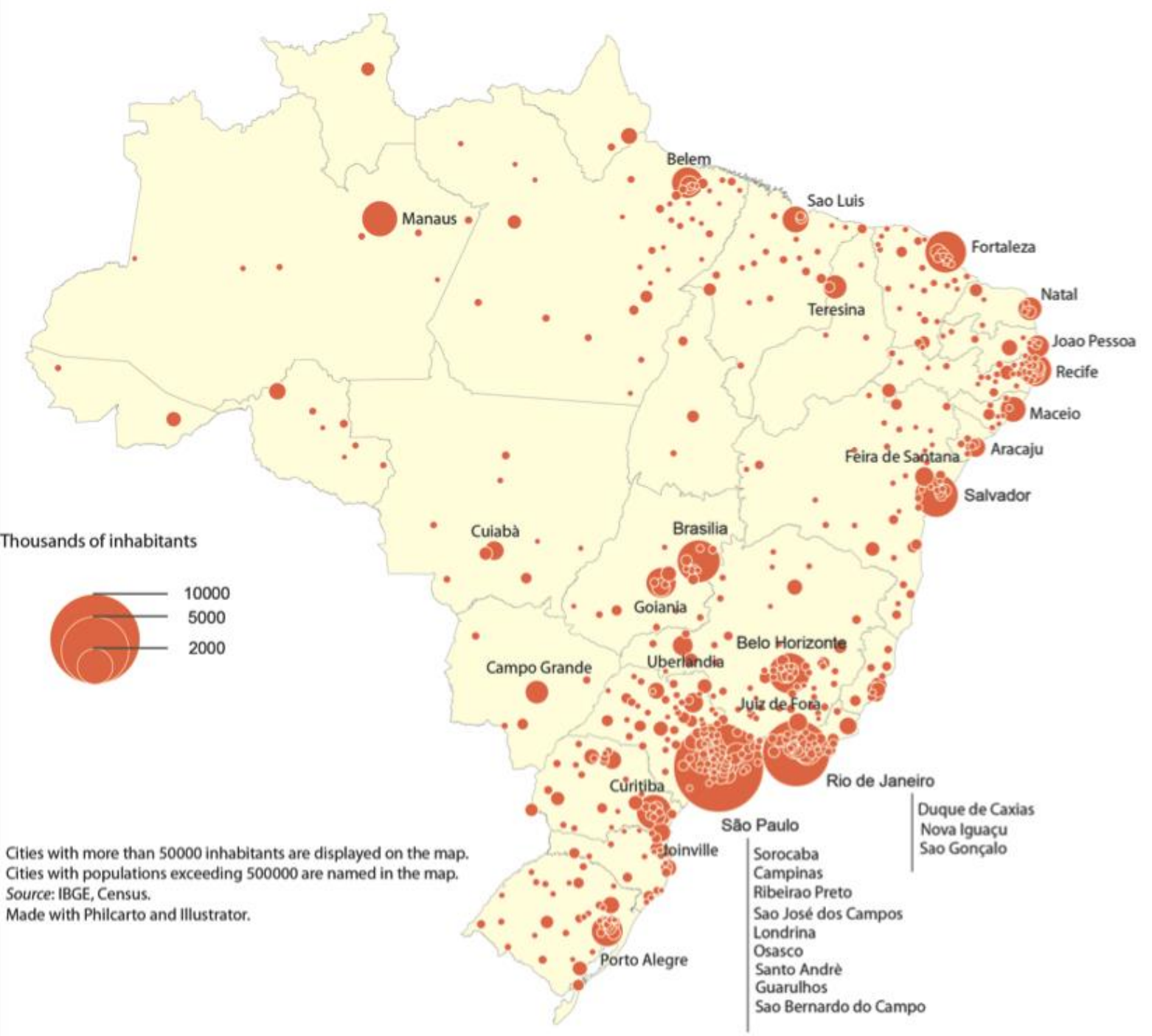

Source: Ignazzi, C (2015). Evolution and urban modeling: a complexity perspective on the Brazilian city system.

Between actors able to solve some of the problems, there is one with strong contradictions: the government. For instance, Villaça (1999, p.183) criticizes the naive idea about the exacerbated planning and points out that since the 1930s "comes up developing in Brazil a vision of the urban world according to which the problems that increasingly manifest themselves in cities are caused by its chaotic growth - without planning - and that an 'integrated' planning or 'set', according to well-defined methods and techniques, would be indispensable for solve them." Indeed, governments expanded forms of planning and public policies that helped to mitigate certain aspects of social problems without solving them, however. Of course, planning alone is not sufficient; in fact the planning is a palliative for the most of cities not just in Brazil but in the world: the problems are situated in the contradictions. In Certain way the cities appear in our minds in Latina America as place of chaos ready to be saved by planning, what is untrue, because most of problems are not in the palliative instrument as we said, but in contradictions in the production of space. According to Costa $(2011$, p.15) there are others possibilities: "A chance to build cities of citizens is change from a material perspective of space (in plans, in planning, structuring or urban production) to a perspective of social space of existence, of the senses, for the sake of collective dignity". 
Capitalism and urbanization have close relations as says Harvey (2014, p.92). The urbanization has been a key means for the absorption of surplus capital and labor throughout the history of capitalism. There is also a very particular role in the dynamics of capital accumulation due to long working hours and turnover and longevity of most investments in the built environment. Also has a geographical specificity such that the production of space and monopolies(spatial) are members of the dynamics of accumulation, not only because of the nature of the changing patterns of the flow of goods in space, but because of the very nature of the spaces and places created and produced in these movements realized. (Harvey, 2014, p.92). Harvey (2014, p156) states that the capitalist urbanization perpetually tends to destroy the city as a common social, politically and livable. According to Penna (2014, p.2) City is the expression of social production, the dynamics of transformation and use of land and natural resources, in reality we live in. The right to the city and spatial justice is articulated inseparably to the process through which the space is produced and reproduced in social relations.

Another key issue in the fight for better conditions takes place in the context of Brazilian social movements. David Harvey (2015, p.14) reminds us of the power and action of urban social movements to promote changes in legislation guaranteeing the right to the city, especially when it comes to housing on the basis of the Brazilian City Statute.

Anyway, the author that dealt with issues related to the right to the city was Henri Lefebvre. The author states in general terms in two of his key books "Right to the City" (2001) and "Urban Revolution" (2004) that the act of living in cities is naturally a revolutionary condition in the sense that it is able to go against the homogenization imposed by capital. The author argues that the spatial justice does not just mean having a home, but the right to life in its multiple dimensions and not just linked to the conditions of material survival, as this would mean just more stimulus to the production of more goods and values. Lefebvre observes that people have right not just the to the City, but others rights as to information, to expression, to culture, to identity in difference (and equality), to self-management, to services. For the author there is a possibility of reappropriation of the unit time and space to overcome the contradictions of the buying and selling practices. However, points out that the city will not be able to overcome all the contradictions but absorb what already exists with all its contradictions. Actually every place can change in different ways.

\section{CONCLUSION}

We have seen how the Brazilian territorial formation was guided by concerns related to defense, maintenance and occupation of the territory. Along its history the production of space was a strong tool to legitimate certain policies of class and keep status quo. During the described historical process, the production of space in the urban centers brought bad consequences to population of many cities in the country and also reactions against precariousness of urban facilities, lack of sanitation, social exclusion, among others. Even with some existent urban centers before the twentieth century is precisely in this century that Brazil expands its urbanization associated to the industrialization projects made by government and by capital. The urbanization process leads to rural exodus, population concentration, metropolization, growth on regional differences and as result many problems. Urban policies were designed to institutionalize palliative instruments. Also public policies were stablished, however, were not able to solve some key urban problems so far.

In our view, the city should be built as collective space which human beings live at their best. Spaces for coexistence, experiences exchanges, public facilities etc. should be available in quality and quantity for everyone. However, cities are spaces where there segregation and expulsion of people in the context of the expansion strategies of capital that has in the production of space its major source of profits.

In fact, Brazil is seen as a country which has one of the largest territories, population and economy and faced several difficulties since its formation through historical processes that include colonial situation, slavery, empire and independence with subsequent establishment of a federal republic, with episodes of autocracy still in the twentieth century. The country went from agricultural exporter to the condition of industrial and agricultural power after a long process of transformations that drove the country's economy. The "state planning" associated with the performance of major domestic and foreign capital in Brazil allowed the country get high growth rates in the twentieth century with similar numbers at times to the current China. An intense process of transformation occurred in the country with the stabilization of the economy post - 1994 and deepening of social policies more structured post -2002.

As conclusion, despite some efforts and relatively successful policies to treat some of the most critical social problems as income concentration, poverty and exclusion of significant segments of the population, the fact is that Brazilian cities are still suffering with bad conditions related to the production of urban space. The ethos 
of capitalist conservative modernization that occurred in Brazil over time was not able to eliminate some of its contradictions and more reflections are necessary in the sense to create better effective policies and improve the well-being of the population. A more critical perspective in Human Geography seems to be necessary. It helps to think in new possibilities as another civilization in Brazil and other countries. The right to the city is the safe way considering that we cannot longer continue to stimulate spatial segregations and limitations to common spaces, public spaces and coexistence in order to share experiences of existence.

\section{ACKNOWLEDGEMENT}

Federal Institute of Brasília (IFB), University of Brasilia (UNB) - Post Graduate Program in Human Geography. Pontifice Catholic University of São Paulo (PUC-SP). To our families. To my Mother and Father in memorial.

\section{REFERENCE LIST}

Brazilian Institute of Geography and Statistics, IBGE (2015) .Census Demographic 2010. http://censo2010.ibge.gov.br/

Carlos, Ana F.A. (2015). Urban Crisis. Sao Paulo. Publisher Context.

City, Cony Lucia Faria (2010) "Ideology, Production of Space and Appropriation of Socionatureza on Lake Paranoá”. In: Paviani, Aldo; Ferreira, et all. (Eds.). Brasilia 50 Years: The Capital Metropolis. Brasilia: Publisher UNB, p. 195-224.

Costa, E.V (2011). "Applied Urban Geography: Possibilities, Utopias and Methodology". Work group. Interventions in Urban Areas in the Period of Globalization. Simpurb XII, Science and Utopia.

Harvey, D. (2014). Rebel Cities: From the Right to the City to the Urban Revolution. Sao Paulo: Martins Fontes - Martins Seal.

Geiger, P. P. (1963). "Evolution of the Brazilian Urban”. Collection Urban Brazil. Vol.1. Brazilian Center for Educational Research. Serie XI. MEC.

Ignazzi, C (2015). Evolution and urban modeling: a complexity perspective on the Brazilian city system. Avaliable at http://geodivercity.parisgeo.cnrs.fr/blog/2012/11/evolution-and-urban-modeling-acomplexity-perspective-on-the-brazilian-city-system/

Lefebvre, H. (2004). The Urban Revolution. Belo Horizonte: Edufmg

(2001). The Right to the City. São Paulo: Centaur.

Moraes, ACR (2005). Territory and History in Brazil. Sao Paulo. Publisher Annablume.

Penna, N. Ferreira, I.B (2014). "Socio-Spatial Inequalities and Areas of Vulnerability in Cities". Mercator, Fortaleza, V. 13, No. 3, p. 25-36.

Report of Cities 2000-2009. "The State of Cities in Brazil". http://www.citiesalliance.org/sites/citiesalliance.org/files/Estado-das-cidades-Brasil-PR-web.pdf

Ribeiro, F. V. (2015). "Contradictory Production of Urban Space and Resistance". In Carlos, et. All. Urban Crisis. St. Paul Publisher Context. P171-186.

Santos, Milton (2013). Urban Poverty. University of São Paulo.

Villaça, F (1999). “A Contribution to the History of Urban Planning in Brazil”. In: Deak, Csaba. The Urbanization Process In Brazil. São Paulo: Publisher of University of São Paulo, 1999, p. 169 - 243. 